seem to be unnecessarily long and parts of them are unnecessarily elementary. Many of the circuits are of historical interest and would not be used in practice, and those areas where instrumentalists are currently making very important advances, such as ENDOR, are, unfortunately, neglected. So, for example, ENDOR is given about thirty-four pages, which is about the same space allocated to vacuum systems. This means that some recent important work in this field has been overlooked. In short, this book, despite its high price, ean be strongly recommended to physicists who wish to learn about the historical development of this technique and who wish to construct their own instruments for special purposes, but will be of little use to the experimentalist who wishes to use electron spin resonance in a routine manner.

M. C. R. SYMONS

\section{ABSTRACT ANALYSIS}

\section{Functional Analysis}

(Academic Press Textbooks in Mathematics.) By George Bachman and Lawrence Narici. Pp. xiv +530. (New York: Academic Press, Inc.; London: Academic Press, Inc. (London), Ltd., 1966.) $116 s$.

THIs book is intended as an introduction to functional analysis, the part of mathematics concerned with infinite dimensional vector spaces. After some preliminary material on finite-dimensional spaces and on metric and general topology, there is a thorough discussion of the fundamental properties of Banach spaces, including the Hahn-Banach theorem, the principle of uniform boundedness, the closely related continuous inversion and closed graph theorems, and related questions. A brief section on spectral theory is followed by an introduction to Banach algebras, going as far as the Gelfand representation. The last third of the book is devoted to spectral theory in Hilbert space; a number of proofs of the spectral theorem for self-adjoint operators (bounded and unbounded) are discussed in detail. The treatment of normal operators contains some novel features derived from recent research.

The book is long for the material it covers; proofs are spelled out in great detail, and there is much incidental comment. There are numerous exercises for the reader, mainly of a quite straightforward character. The book will be useful for reference to student and teacher alike, but might be found rather heavy going by a beginner wishing to acquaint himself with the elements of the subject.

F. SмIтнIES

\section{METAL-METAL COMPOUNDS}

\section{Intermetallic Compounds}

Edited by J. H. Westbrook. (Wiley Series on the Science and Technology of Materials.) Pp. xvii +663 . (New York and London: John Wiley and Sons, 1967.) $235 s$.

DR WESTBRooK claims, rightly, that this is the first comprehensive treatment of this subject in fifty years. It is therefore all the more welcome.

Considerable effort is now being directed towards metallic compounds of all types, largely as a result of the state of near exhaustion in the further development of metallic alloys. This volume deals mainly with the structure, transformations and properties of metal-metal compounds, but because many of these are operative agents in improvement of the properties of metallic alloys, they are of interest to both metallurgists and materials scientists.

The editor presents a historical sketch in the first chapter, concise and informative, and rather unusual for a book originating in the United States, where history tends to be more introverted. Excellent reviews of bonding theory and experimental evidence for bonding characteristics are given in the second part, and although one or two are a little too brief, they form an excellent introduction to the subject for the research student. The chapters in the third part, on crystal structure, incorporate some well executed illustrations to assist understanding of the text in a way which puts the average undergraduate textbook to shame. Many matters of metallurgical interest are featured here.

The fourth part of the book, on micro- and sub-structure, is short, and perhaps the least successful is the chapter entitled "Lattice Defects", which adds little and omits much which is relevant. Formation and stability are well covered in the fifth part and so are kinetics and transformations in the next part. The final part of the book comprises seven chapters on properties, from mechanical to super conductivity, and much of this will be well thumbed in library copies. It is disappointing, however, to find little reference to thermal properties except for thermoelectricity, but in recent years this has become almost a constant feature of any book dealing with the properties of materials. It would appear that only mechanical strength and electronic applications are of any significance to industrial and academic research alike.

I welcome an index including not only author and subject entries but also a completelist of the compounds mentioned. The star-studded international cast includes twenty-four authors from the United States and nine from other countries, all in Europe, but the price of roughly $4 d$. a page is, by the standards of research costs, very cheap.

C. R. TOTTLE

\section{RULES FOR CHEMISTS}

\section{Chemists and the Law}

By F. A. Robinson and F. A. Amies. Edited by H. M. Bunbury. Pp. $x x+231$. (London: E. and F. N. Spon, Ltd., 1967.) 408. net.

THE term "chemist" in the context of this recent publication must very properly be accepted as covering a multitude of scientific disciplines, for there is much in this book which will prove of the greatest value and interest, not only to academic and industrial chemists, but to biochemists, physicists, pharmacists, engineers, factory managers and many others. Indeed, this book can also be strongly recommended for the earnest attention of the intelligent layman, because it provides a wealth of legal information regarding such diverse matters as "Contracts of Employment", "Negligence", "Pollution", "Food Statutes", "Agricultural Substances", "Explosives", "Medicines and Dangerous Drugs", "Radioactive Substances", "Patents", "Copyright" and so on. The legislative aspects of all these matters are discussed most authoritatively and comprehensively, particular attention being drawn to specific differences between the statute law of England and Wales as compared with the corresponding provisions of the Scotland and Northern Ireland Acts. Numerous legal cases are cited which constitute precedents and which provide the reader with some prognostication of the judgments which might conceivably be given when legal cases of a certain pattern come before the courts.

The organization of the British courts system is clearly outlined; details are given of the preparation for trial and hearing, of the duties and responsibilities of such people as expert witnesses, assessors and scientific advisers. The fundamental items of statute law, for example, Food and Drugs Act, Patents Act, and the provisions of a host of other important acts of parliament and statutory instruments are given in the greatest detail, accompanied 